\title{
Significance of Research on Time Quota of Enterprise in China
}

\author{
Huiping Mu, Yingying Han and Yaping Huo \\ School of Management Engineering, Zhengzhou University, No.100 Science Avenue, China \\ 1793074582@qq.com
}

Keywords: work quota, labor productivity, interests of workers, maximize profit

\begin{abstract}
The quota is the main tool to balance the interests of the enterprise and the employees. In order to stimulate the labor enthusiasm of the workers, improve the labor productivity, allocate the expenses reasonably and improve the economic efficiency of the enterprises, companies should formulate reasonable working hours' quota and working hours' management system. In the production mode of Chinese enterprises, there is an imbalance in the formulation of working hours' quotas, and the development speed is relatively slow, the labor efficiency is relatively low, and the unequal level of quota has affected the enthusiasm of the workers and the maximization of the profits of the enterprises. Work quota is the basis for balancing the interests of enterprises and the interests of workers and staff. Therefore,
\end{abstract} companies need a more objective and scientific development of work quotas.

\section{INTRODUCTION}

This study is mainly because the current increasingly fierce market competition in China's market, the main performance in the enterprise of science and technology, quality, intellectual property rights and benefits of competition, enterprises must implement modern enterprise management system of science and technology innovation and scientific management. Man hour quota management is the basic management work of each enterprise. Doing a good job hour quota can reduce costs, improve efficiency, and improve the competitive advantage of enterprises. In order to allow business managers to measure and calculate the labor productivity scale, from the efficiency of work to find the impact of time fixed time, the use of certain scientific methods and organizational improvements to reduce labor intensity, improve working efficiency, and constantly break through the quota level, to promote the development of production.

\section{THE SITUATION OF WORK QUOTA IN CHINESE ENTERPRISES}

Enterprise work quota is the basis and conditions for the implementation of economic responsibility system, strengthening enterprise management, and implementing the principle of "doing everything according to work". With the development of economy and the reform of enterprises, the quota is very important in the production process. The development of the wage system and the improvement of labor output need to be based on reasonable and perfect working hours' quotas. The necessary working hours consumption will be based on the completion of the different circumstances of the quota, pay different wages, with the 'distributing according to work' principle to promote the staff consciously or excess to complete the fixed as a goal. Unemployed working hours consumption will not be included in the workers' labor time, such as downtime, nest workers and so on (Juan Tang,2013). Enterprises only to develop a reasonable working hours quota, in order to make it the maximum profit.

At present, China's market competition is becoming increasingly fierce, mainly in the enterprise technology, quality, intellectual property and efficiency of competition, enterprises must implement scientific and technological innovation and scientific management of modern enterprise management system. Man hour quota management is the basic management work of each enterprise. Doing a good job hour quota can reduce costs, improve efficiency, and improve the competitive advantage of enterprises. In order to make the enterprise managers have a measure and calculate the labor productivity scale, who found that the influence of time quota time from work efficiency, to reduce the labor intensity of the use of certain scientific method and improve the organization, improve working efficiency, continue to break the quota level, to promote the development of production.

In Chinese enterprises, some enterprises divide the quota department into the planning department or the technical department. Ship Corporation clearly pointed out: the amount of personnel first is the technical staff, but also the management staff, and the cause of the same technical staff treatment. Some enterprises regard quota work simply as statistical work, regard quota personnel as auxiliary personnel, lower treatment, and dampen the enthusiasm of quota personnel. And even individual enterprises to cancel the quota management, that the fixed staff is redundant staff (Qingli Zhu,2012). Facts have proved that the good operation of enterprises need to set the amount of personnel to the enterprise plan. With the establishment of modern enterprise system, quota management is bound to all levels of management attention, truly enterprise labor justice system work, arouse the enthusiasm of workers, creating technology innovation, bring new features of enterprises.

At present, there are still a lot of problems with hourly quota management:

(1) Business management coverage is too narrow

For a long time, the formulation of working hours' quotas is mostly based on the production sector, and few links with neighboring departments cannot be used 
flexibly. It is almost impossible to proceed from the whole of the enterprise.

(2) Management means to administrative order and control

The traditional time quota are basically rely on instructions and control as the foundation, management means and according to time. The standard punch system is this kind of management method, efficiency and costs consciousness is not deep in the consciousness of workers and managers. So the traditional working hours quotas are based on the habits of workers to estimate the workload, such as the similar experience estimation method.

(3) Low level of quota

The current man hour quota level is basically "average advanced" level. The project cost management requires the level of man hour quota to reach "scientific and advanced"(Xinai Liu, 2010), so there is a certain gap between the actual and the working hours on the market, and there is no accurate project labor cost standard for the enterprise reference.

\section{THE SIGNIFICANCE OF WORKING HOUR QUOTA}

In the manufacturing industry, labor is an operator cannot ignore the important cost of labor costs to a large extent determine the plant management is good or not. Whether to reduce labor costs to improve work efficiency is the key link of corporate profitability and the best way to promote the active work of workers is mainly distributed according to work reward and punishment system. The implementation of this system must have a set of objective criteria, that is, standard working hours, which is the subject to study the meaning and purpose.

Its main significance and use mainly include the following:

(1) Man hour quota is an important means to organize production and improve labor efficiency

In modern enterprises, in order to reasonably configure certain personnel and materials, the time quota can completely solve the relationship between division of labor and cooperation, through the analysis and balance production line of work, the formation of an organic whole to coordinate production process, ensure the production process balance, high efficiency, the rhythm of the whole transport line (Xun Gong, 2011). Labor quota is an important basis for enterprises with capacity. Nowadays, as long as the production of enterprises will need a certain amount of labor, the amount of labor required to be fixed on time to complete. It can measure workload and labor intensity of the labor positions, so as to realize the optimization of structure of working posts and capacity. This can avoid the waste caused again and more personnel than work available, can satisfy the need of production and work, make the best and its effect.

(2) The quota is the scale of the distribution according to work

To implement the principle of distribution according to work, it is necessary to carry out strict supervision of the workers' labor time. The standard time and normal time is helpful for scientific and rational calculation and formulation. Work quota is the standard measure of measuring and assessing workers' labor. The completion of the labor force of the workers is the standard of their labor status and reward.

To implement the principle of distribution according to work, we must strictly supervise the labor time of the workers. Scientific and reasonable calculation includes formulation of standard time and normal time (Shuping Yi, 2010). Man hour quota is a standard measure to measure and evaluate labor amount of workers. The amount of work done by the workers is the standard of their working conditions and the remuneration they receive.

(3) Man hour quota is an important means to calculate labor cost and improve economic benefit

To calculate the profit and loss balance, this paper makes a comprehensive comparison and analysis of the input and output of enterprises, and strives to get the most output with the least input. If the quota is not real construction, the production process of the investment and consumption will not be clear and detailed how to achieve cost-effective, reduce costs and improve efficiency will not start, for the enterprises operating conditions without clear aims.

(4) Man hour quota is an important basis for enterprise customized staff

Scientific and reasonable working hours' quota is an important basis for enterprises with reasonable staff. According to the custom staff is based on the quota to select the appropriate staff, in order to make the best use of their personnel, blending, make the enterprise personnel. For more and more talents, customization by post has become the trend of the times, so doing a good job hour quota is also an important means to improve the competitiveness of enterprises.

\section{THE TREND OF CHINA 'S ENTERPRISES' LABOR QUOTA}

At present, the standard quota and grading pipe are adopted in our country's work hour quota. This puts a higher demand for hourly quota managers. The personnel involved in the management must be highly qualified professionals with higher research level and efficiency management.

Methods and techniques need to keep pace with man hour quotas (Aixin Liu,2010). Modern enterprises have begun to improve and optimize the production process through the improvement of production factors and the introduction of knowledge production capacity, rather than the traditional increase in the number and intensity of labor. Enterprises from the experience of assessment method to the scientific rationalization of development, and gradually formed a good corporate culture, to tap the potential and improve efficiency to increase efficiency of the purpose.

Standardized and standardized scientific management methods are also significant for the quota management. Standardized quota for the standardization of staff operations and work enthusiasm have a greater role in promotion (Mingxia Gao, 2010). In the process of 
standardized development, we can find the shortcomings of enterprises, and further improve and optimize the enterprises. To standardize the chemical engineering practice, the key is to regulate human behavior, so it is the management of human subject. The purpose of standardization is to cultivate staff's efficiency consciousness, procedure consciousness, standard consciousness and competition consciousness, arouse the enthusiasm and creativity of the staff, and enhance the vitality of the enterprise. Moreover, the enterprise quota management will also be internationalized and information-based.

\section{CONCLUSIONS}

The purpose of the quota study is to determine the labor consumption standard of the unit product, which improve the labor efficiency of the enterprise and promote the economic growth of the enterprise. It is a comprehensive management work combining technology and economy. The research of time is the basis of input information and capacity planning of employee salary quota and labor quota, which plays an important guiding role for high-level decision-making. The enterprise should give full play to the labor enthusiasm of the workers, scientific and rational use of labor resources, improve production organization and labor organizations, to maximize the savings of materialized labor and living labor consumption, the economic benefits achieved expected target.

\section{REFERENCES}

[1] Aixin, Liu, Xun, Dai, Baojie, Shen. J, 2010. Understanding of the generation of enterprise of man hour quota management review.

[2] Juan, Tang. D, 2013, Research on time model of job factors in mass customization environment.

[3] Mingxia, Gao, Mingda, Zhang, Shiqing, Feng, Zhuo, Zhang. $\mathrm{D}$, 2010.The application of man hour quota in enterprise management. Beijing Jiaotong University.

[4] Qingli, Zhu. J, 2012. The application of labor quota in the machinery manufacturing industry. Value engineering, 2012 (16).

[5] Shuping, Yi. M, 2010. Basic industrial engineering. Mechanical Industry Press, Beijing, first edition.

[6] Xinyue, Xia.J,2007. The principle and application of time study. Industrial engineering and management, 2007 (6) 47-50.

[7] Xun, Gong.J,2011. On the formulation and function of man hour quota in modern enterprises. Science and technology. 